Notes

The Journal of Heredity 75:411-412. 1984.

\section{An ksozyme marker for resistance to bean yellow mosaic vinus in Pisum sativum}

\author{
- N. F. Weeden, R. Provvldentl, and \\ G. A. Marx
}

ARSTRACT: Linkage between Pgm-p, the locus speclfying the plastld specific phosptioglucomutase, and Mo, the locus controlling resistance to bean yellow mosaic virus (BYMV), was investtgated in the garden pea, Plsum sativum L. Both genes are known to be on chromosome 2 and exhibit linkage with two morphological marker loci, $K$ and $W b$. Our results indicate that the gene order is: $W b-K-P g m-P-M O$. A map distance of approximately two recombinant units was dotermined for the Pgm-p-Mo linkage, suggesting that the enzyme locus can be used as a genetic marker for resistance to BYMV.

THE POTENTIAL use of polymorphic enzyme loci as genetic markers has been recognized ever since the simple genetic basis of allozymic variants was demonstrated 2.8 . The technique was first applied in the tomato after Rick and Fobes ${ }^{5}$ described the tight linkage between an acid phosphatase locus and the gene bestowing nematode resistance. Few other examples of a close linkage between a polymorphic enzyme locus and a commercially important trait are available. However, polymorphic isozyme loci have been used to analyze the genetic basis of a number of quantitative characters 9,10 . The partial isozyme linkage map we described for Pisum sativum L. ${ }^{12}$ should provide markers for genes controlling several commercially important characters. We are especially interested in those genes affecting disease resistance, for such characters are often revealed only after elaborate tests.

Yen and Fry ${ }^{13}$ demonstrated that certain pea cultivars carried resistance to bean yellow mosaic virus (BYMV). Genetic tests showed that the resistance was conferred by a recessive allele at $M o$, a locus on chromosome 2 about five map units from a well-characterized flower mutant,

The authors are affiliated with the Department of Horticultural Sciences (N.F.W. and G.A.M.), and the Department of Plant Pathology (R.P.), New York Agricultural Experiment Station, Comell University, Geneva, NY 14456.

1984, American Genetic Association. $k^{3}$. Further studies on the mo gene have demonstrated that it, or a tightly linked gene, confers resistance to watermelon mosaic virus $2^{7}$. The relatively close linkage between $k$ and $m o$ has permitted the former to be used as a marker for $m o$ in segregating progeny. However, several disadvantages are associated with using $k$ as a marker. The mutant phenotype is fully recessive, permitting the differentiation of only two progeny classes, and the phenotype is expressed in the flower, thus delaying the screening operation until the plants bloom. We report here a linkage between $m o$ and the locus Pgm-p, which codes for the plastid specific form of phosphoglucomutase (PGM-2, EC 2.7.5.1). The distinctive properties of isozyme loci such as codominant and early expression of alleles and freedom from pleiotropic or epistatic interactions would indicate that Pgm-p may be superior to $k$ as a marker for mo.

\section{Materials and Methods}

Five seed, representing the $F_{3}$ generation from B77-254 $\times$ A78-237 and the reciprocal cross, were obtained from each of 85 plants from the $F_{2}$ population $A$, described by Weeden and Marx ${ }^{12}$. The line B77-254 is resistant to BYMV (mo/ $\mathrm{mo}$ ), homozygous for the fast allele of $\mathrm{Pgm}-\mathrm{p}$ and homozygous dominant at $K$ and $W b$. The inbred line A78-237 is susceptible to BYMV, homozygous slow at $P g m-p$, and exhibited the recessive phenotypes for $k$ and $w b$. Seed were germinated in an artificial soil mix and grown in a greenhouse at $20-23^{\circ} \mathrm{C}$. Seedlings were mechanically inoculated with a type strain of $\mathrm{BYMV}^{6}$ on the first two fully expanded leaves. To assure infection in all susceptible genotypes, plants were subsequently reinoculated on the third and fourth leaves. Inoculum was prepared by triturating leaves of BYMV-infected pea plants with $0.05 \mathrm{M}$ phosphate buffer $\left(\mathrm{K}^{+}\right), \mathrm{pH}$ 7.0. Control plants from each parental line as well as two check lines, 'Bonneville' ( $R$ ) and 'Ranger' $(S)$, were treated similarly to the $F_{3}$ plants.

The genotype at Pgm-p was determined on young leaf tissue by starch gel electrophoresis on a pH 8.1 tris-citrate/lithium borate gel system as described previously" ${ }^{1}$.

Epicuticular wax development on both surfaces of the stipules, the lower surface of the leaflets, and the pods is markedly reduced in $w b / w b$ plants; stem wax also is somewhat re- duced ${ }^{1}$. The phenotype of mutant plants can be scored in the seedling stage. In $k / k$ plants the wings (alae) of the flowers are smaller than normal and tightly appressed to the keel ${ }^{1}$. The $k$ phenotype was determined as soon as a plant began to flower.

Linkage estimates were calculated as described previously 12 .

\section{Results}

Although all seed selected from the $F_{2}$ plants appeared normal, eight sets of five did not germinate and another seven sets produced only one or two mature plants. Of the remaining 70 sets, 66 exhibited 100 percent germination, three gave four seedlings and one produced three seedlings. A total of $355 \mathrm{~F}_{3}$ plants were scored for those characters ( $w b, m o$, and PGM) that were expressed in young plants. Homozygous $(\mathrm{Mo} / \mathrm{Mo})$ and heterozygous $(\mathrm{Mo} / \mathrm{mo}$ ) plants susceptible to BYMV responded to viral infection with a persistent yellow mosaic and stunting. Plants possessing $\mathrm{mo} / \mathrm{mo}$ were highly resistant and were free of local and systemic infection. A number of susceptible plants died before flowering so that the data for $k$ were not as complete. Control plants responded as anticipated, with all five B77-254 plants showing a resistant phenotype and all A78-237 plants being susceptible.

Each character scored gave phenotypic ratios in the $F_{2}$ and $F_{3}$ generations close to those expected for two alleles segregating at a single locus (Table I). The ratios observed in the $F_{3}$ were slightly biased in favor of the recessive phenotype because only sets exhibiting both phenotypes were included in the calculation. For instance, a family consisting of three recessive and two dominant phenotypes would be included in the summation, but a progeny in which all five plants exhibited the dominant phenotype would be scored as not segregating even though there was a significant probability ( 23.7 percent) that such sets were derived from a heterozygous parent and would show segregation if a larger sample had been taken.

Recombination frequencies between $M o$ and each of the three other loci were calculated using the genotypes of the $F_{2}$ plants as determined with the aid of $\mathrm{F}_{3}$ progeny tests (Table II). This procedure permitted the identification of most $F_{2}$ individuals heterozygous at $M o, W b$, or $K$, as described above. The relative recombination
Table L. Segregation of alleles at $M o, K, W b$, and $P_{g m-p}$ for both the $F_{2}$ and $F_{3}$ generations

\begin{tabular}{|c|c|c|c|c|c|c|c|c|}
\hline \multirow[b]{3}{*}{ Loci } & \multicolumn{8}{|c|}{ No. plants with designated phenotype* } \\
\hline & \multicolumn{4}{|c|}{$F_{2}$ plants } & \multicolumn{3}{|c|}{$\mathrm{F}_{3}$ plants } & \multirow[b]{2}{*}{$x^{2 \dagger}$} \\
\hline & - & $\mathrm{H}$ & + & $x^{2}$ & - & $\mathrm{H}$ & + & \\
\hline Mo & 17 & & 54 & 0.04 & 48 & & 90 & $7.85^{* *}$ \\
\hline$\kappa$ & 24 & & 61 & 0.47 & 34 & & 76 & 2.05 \\
\hline$w b$ & 19 & & 55 & 0.02 & 41 & & 92 & 2.41 \\
\hline$P g m-p$ & 22 & 44 & 17 & 0.35 & 36 & 84 & 50 & 2.33 \\
\hline
\end{tabular}

* Designations: recessive phenotype or homozygous slow $=-$; heterozygous $=\mathrm{H}$; dominant or homozygous fast $=+$

${ }^{4}$ Bias not corrected for in $\chi^{2}$ calculations

** $P<0.01$, but see above footnote and discussion in text 
Table II. Joint segregation data in the $F_{2}$ population for pairwise comparisons of the loci Mo, $P g m-p, K$, and $\mathrm{Wb}$

\begin{tabular}{lrrrrrrrrrrrrrr}
\hline & \multicolumn{1}{c}{ No. plants with designated phenotype } & \multicolumn{3}{c}{ Recomb. } \\
Loci & $\mathrm{N}$ & $-/-$ & $-/ \mathrm{H}$ & $-/+$ & $\mathrm{H} /-$ & $\mathrm{H} / \mathrm{H}$ & $\mathrm{H} /+$ & $+/-$ & $+/ \mathrm{H}$ & $+/+$ & & fract. & SE \\
\hline Mo:Pgm-p & 65 & 0 & 2 & 15 & 0 & 29 & 1 & 19 & 0 & 0 & 2 & 1.24 \\
Mo:K & 60 & 0 & 2 & 15 & 0 & 16 & 8 & 18 & 1 & 0 & 9 & 2.75 \\
Mo:Wb & 69 & 1 & 4 & 16 & 1 & 16 & 12 & 15 & 4 & 0 & 18 & 3.68 \\
Pgm-p:K & 67 & 20 & 1 & 0 & 1 & 25 & 5 & 0 & 0 & 15 & 5 & 1.93 \\
Pgm-p:Wb & 71 & 15 & 4 & 0 & 4 & 20 & 13 & 0 & 3 & 12 & 18 & 3.63 \\
\hline
\end{tabular}

* Designations as described in Table 1

frequencies between loci indicated that the gene sequence is: $W b-K-P g m-p-M o$. Pgm-p exhibited tighter linkage with $M o$ (2 percent recombinants) than with $K$ (5 percent recombinants).

The linkage $\boldsymbol{W b}-\boldsymbol{K}-\boldsymbol{M o}$ is consistent with previous findings ${ }^{4}$; however, in order to determine if our linkage results were significantly biased by treating $F_{2}$ plants with nonsegregating progeny as homozygous at the particular locus (e.g., $W b$, $K$, or $M o$ ), two additional linkage calculations were performed. These latter calculations were based only on observable phenotypes within a generation. The first considered only data obtained from the $\mathrm{F}_{2}$ population, treating the $m o$, $w b$, and $k$ phenotypes as strictly dominant and recessive. The second linkage calculation was based on $\mathrm{F}_{3}$ generation data alone and was limited to those progenies segregating both at $M o$ and at least one of the other linked loci. Both calculations (data not shown) gave a gene order identical to that obtained from results presented in Table II. Furthermore, in both cases $P g m-p$ was more tightly linked to $M o$ (4 percent recombinants in the $F_{2}$ and 1 percent recombinants in the $\mathrm{F}_{3}$ ) than to $K$. This consistency implies that our original linkage results accurately reflect the gene order and approximate recombination frequencies among the four loci.

\section{Discussion}

The demonstration that $P g m-p$ was located approximately five map units from $K$ on the side opposite $W b^{12}$ led to the suggestion that this isozyme locus could serve as an excellent marker for mo, the locus controlling resistance to BYMV. The data presented in this study confirm this possibility and indicate that the distance between $P g m-p$ and $M o$ is about two map units. Considering all $355 \mathrm{~F}_{3}$ plants analyzed for both characters, the mo phenotype would have been incorrectly predicted by the PGM-2 phenotype in only 11 instances, of which nine were progeny of the three recombinant $F_{2}$ plants. Pgm-p proved to be superior to $k$ for following the inheritance of alleles at Mo not only because of the tighter linkage between $P g m-p$ and $M o$ but also because of the ability to distinguish all three classes of progeny (both homozygotes and the heterozygote) and obtain these results on young seedlings, even before it was possible to determine the $m o$ phenotype of the plants. Pgm-p also should be useful as a marker for resistance to watermelon mosaic virus 2 whether or not mo or a tightly linked gene is responsible for this resistance.

Infection of the leaf tissue by the virus did not affect the PGM phenotype observed after electrophoresis (data not shown), and this phenotype was stable throughout plant development, being discernible in stem and petal as well as leaf tissue. Under the stated conditions for electrophoresis, the slow form of the cytosolic PGM isozyme exhibits a mobility very similar to the fast allozyme of PGM-2 (see discussion in Weeden and Gottlieb $^{11}$ ). This overlapping of forms may lead to difficulties in the interpretation of zymograms when both $P g m-c$ and $P g m-p$ are segregating. We have found that continuing the electrophoresis operation until the borate front has migrated $12-13 \mathrm{~cm}$ (requiring approximately 5 hours) will help resolve the individual bands and facilitate interpretation of the phenotypes.

The method of analysis of the $F_{3}$ data introduced a slight bias favoring the homozygous dominant phenotypes. We did not correct for this bias in our calculations of chi-square values (Table I) or the recombination fractions (Table II). Correcting for the bias would increase the number of wild-type (+) $F_{3}$ plants in Table I (thereby decreasing the chi-square value). Similar corrections in Table II would have slight effects on the distribution of progeny among the categories. However, the calculated map distances would exhibit only minor changes, and the relative order of the loci would not be affected.

\section{References}

1. BLIXT, S. The pea. In Handbook of Genetics, vol. 2, R. C. King, Ed. Plenum Press, NY. p. 181-221. 1974.

2. INGRAM, V. M. Gene mutations in human haemoglobin: the chemical difference betwoen normal and sickle cell haemoglobin. Nature 180:326-328. 1957.

3. LAMPRECHT, H. The variation of linkage and the course of crossingover. Agri Hort. Genet. 6:10-48. 1948.

4. Marx, G. A. and R. Provvidenti. Linkage relations of mo. Pisum Newsl. 11:28-29. 1979.

5. RICK, C. M. and J. F. Fobes. Association of an allozyme with nematode resistance. Rep. Tomato Genet. Coop. 24:25. 1974.

6. SChroeder, W. T. and R. Provvidenti Evaluating Pisum satioum for resistance to pea mosaic. New York State Agr. Exp. Sta. Bul. 806. 1964.

7. — and _- A common gene for resistance to bean yellow mosaic virus and watermelon mosaic virus 2 in Pisum sativum. Phytopathology 61 : 846-848. 1971

8. SHAw, C. R., F. N. SYNER, and R. E. TASHIAN. New genetically determined molecular form of erythrocyte esterase in man. Science 138:31-32. 1962.

9. STuber, C. W., M. M. GoOdMAN, and R. H. MOLL. Improvernent of yield and ear number resulting from selection of allozyme loci in a maize population. Crop Sci. 22:737-740. 1982.

10. TANKSLEY, S. D., H. MEdina-FilHo, and C. M. RICK. The effect of isozyme selection on metric characters in an interspecific backcross of tomato-basis of an early screening procodure. $T A G$ 60:291-296. 1982.

11. WeEden, N. F. and L. D. Gottlieb. The genetics of chloroplast enzymes. J. Hered. 71:392396. 1980.

12. - and G. A. MARX. Chromosomal locations of twelve isozyme loci in Pisum sativum. J. Hered. 75:365-370. 1984.

13. YEN, D. E. and P. R. FRY. The inheritance of immunity to pea mosaic virus. Australian J. Agr. Res. 7:272-281. 1956. 